\title{
Critical examination of knowledge to action models and implications for promoting health equity
}

\author{
Colleen M. Davison ${ }^{1 *}$, Sume Ndumbe-Eyoh ${ }^{2}$ and Connie Clement ${ }^{2}$
}

\begin{abstract}
Introduction: Knowledge and effective interventions exist to address many current global health inequities. However, there is limited awareness, uptake, and use of knowledge to inform action to improve the health of disadvantaged populations. The gap between knowledge and action to improve health equity is of concern to health researchers and practitioners. This study identifies and critically examines the usefulness of existing knowledge to action models or frameworks for promoting health equity.

Methods: We conducted a scoping review of existing literature to identify knowledge to action (KTA) models or frameworks and critiqued the models using a health equity support rubric.

Results: We identified forty-eight knowledge to action models or frameworks. Six models scored between eight and ten of a maximum 12 points on the health equity support rubric. These high scoring models or frameworks all mentioned equity-related concepts. Attention to multisectoral approaches was the factor most often lacking in the low scoring models. The concepts of knowledge brokering, integrative processes, such as those in some indigenous health research, and Ecohealth applied to KTA all emerged as promising areas.

Conclusions: Existing knowledge to action models or frameworks can help guide knowledge translation to support action on the social determinants of health and health equity. There is a need to further test existing models or frameworks. This process should be informed by participatory and integrative research. There is room to develop more robust equity supporting models.
\end{abstract}

Keywords: Health equity, Knowledge translation, Public health interventions, Health inequalities

\section{Introduction}

Each year, preventable disease and disability and shortfalls in the determinants of health take the lives and diminish the health and well-being of millions of people globally $[1,2]$. Inequalities in health and social circumstances across populations persist within and between countries and regions. Groups experiencing social and economic exclusion that leads to unequal access to health and its determinants include, for instance, people living in poverty, people with disabilities, racialized peoples, and Indigenous peoples who are disproportionately affected by poor health and shorter lives [3]. The resulting health inequities are

\footnotetext{
* Correspondence: davisonc@queensu.ca

'Department Public Health Sciences, Queen's University, 63 Fifth Field

Company Lane, Kingston, ON K7L 3N6, Canada

Full list of author information is available at the end of the article
}

differences in health that are judged to be unfair or the result of some form of historical or contemporary injustice [4]. They have also been defined as systematic, unfair and avoidable inequalities [5]. Striving for health equity means working so that everyone can reach their full health potential and not be disadvantaged from attaining this because of their class, socioeconomic status or other socially determined circumstance [6, 7].

Different forms of knowledge and effective interventions exist to address many health concerns and inequalities however, awareness, uptake and use of these can be poor and poorer still with respect to interventions to improve health across social gradients [8].

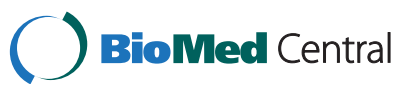

(c) 2015 Davison et al. This is an Open Access article distributed under the terms of the Creative Commons Attribution License (http://creativecommons.org/licenses/by/4.0), which permits unrestricted use, distribution, and reproduction in any medium, provided the original work is properly credited. The Creative Commons Public Domain Dedication waiver (http:// creativecommons.org/publicdomain/zero/1.0/) applies to the data made available in this article, unless otherwise stated. 
The difference between what is known about a particular health issue or possible intervention, and what is being done for health promotion and disease prevention is termed the "know-do gap". This gap between knowledge and action is of prime concern to public health researchers and practitioners, and pertains increasingly more prominently to what is not being done to improve health equity including improving health for disadvantaged populations. "Knowledge to action" is a broad term used to refer to the process of bridging the know-do gap. This concept has been described in many different ways including the translation, dissemination, implementation, transfer and exchange of knowledge, the diffusion of an innovation or idea, and the use of knowledge or research evidence to inform decision making [9-11]. Knowledge to action scholarship has increased significantly over the past 20 years $[6,12,13]$. In 1990, fewer than a hundred articles were retrieved in a knowledge translation keyword search in Medline. In February 2006, several thousand articles were found with the same search strategy [14]. In August 2012, we retrieved nearly 110,000 articles with the keywords: knowledge translation, knowledge transfer, dissemination, evidence-based, and knowledge to action. While there have been many papers on knowledge to action, there has been limited research that explores which strategies or components may be most effective for supporting health equity [15]. The evaluations that do exist have primarily occurred for evidence-based medical practice in high-income countries [16]. There is significant potential for knowledge to action theory, models, frameworks and methodologies to contribute to the discourse, and inform action to address health inequities more widely [17].

In the past few years, there have been key publications such as Closing the Gap in a Generation: Health equity through action on the social determinants of health [1] and Integrating Social Determinants of Health and Health Equity Into Canadian Public Health Practice [2] that have specifically called for bridging the know-do gap for health equity gains. Knowledge to action approaches can bridge the gap between what we know about health inequities and what is being done to address and reduce them. Specifically, there is a need for an explicit focus on equity in decision and policy making, for instance with respect to distribution of resources, prioritization of issue and targeting of interventions Inclusive and participatory approaches recognizing varied forms of knowledge and perspectives; interaction across jurisdictions and sectors; and consideration of the social, political and economic factors that support or deter efforts towards health equity are required at many levels of decision making $[1,2]$.

The purpose of this analysis was to identify existing knowledge to action models or frameworks and critically examine a promising subset of them as to their utility for promoting or supporting health equity.

\section{Methods}

A scoping review was conducted by CMD and a research associate Ariel Pulver (AP) for preexisting knowledge to action models or frameworks. This was not designed to be an exhaustive review, but to generate a group of recent models or frameworks that could be assessed in relation to health equity. Given the numerous conceptualizations and diverse terminologies [9] used in the field, the search and subsequent accumulation of models or frameworks was not limited to "knowledge to action" itself but included other derivations and conceptualizations (i.e., "dissemination"; "knowledge translation"; "knowledge transfer and exchange"; "knowledge utilization"). Team members and a University librarian were consulted and models or frameworks were decided to be identified in three ways:

1) a title and abstract keyword search in four prominent health science or general databases (Ovid MEDLINE(R), PsycINFO, AMED Allied and Complementary Medicine and EBSCO Host CINAHL), and on Google Scholar;

2) a review of the reference lists and cited articles of identified papers; and

3) discussions with experts in the field

Modifications of the following search string were used for the database searches: ("dissemination" or "knowledge to action" or "knowledge translation" or "knowledge transfer").mp. and ("model" or "framework").m_titl. The database searches were limited by year (1997-present) and language (English). Articles were included if they contained a description, discussion, or critique of a specific model or framework for some derivation of "knowledge to action". Results of this search strategy are outlined in Table 1. Titles and abstracts were reviewed for all identified papers by CMD and AP, those deemed potentials for inclusion were reviewed in full text by CMD and AP. The search flow diagram is outlined in Fig. 1.

Table 1 Search location and results

\begin{tabular}{ll}
\hline Search Location & Search Results \\
\hline $\begin{array}{l}\text { Ovid MEDLINE(R) 1944 to August Week 2 } \\
2012\end{array}$ & 464 relevant documents \\
PsychINFO 1967 to August Week 2 2012 & 89 additional documents \\
$\begin{array}{l}\text { AMED (Allied and Complementary } \\
\text { Medicine) 1985 to August 2012 }\end{array}$ & 3 additional documents \\
EBSCO Host CINAHL August 2012 & 89 additional documents \\
Google Scholars (first 6 results screens) & 26 additional documents \\
& (no year limitation) \\
Review of reference list of identified & 18 additional documents \\
documents & (no year limitation) \\
Expert consultation & 4 additional documents \\
& (no year limitation) \\
\hline
\end{tabular}




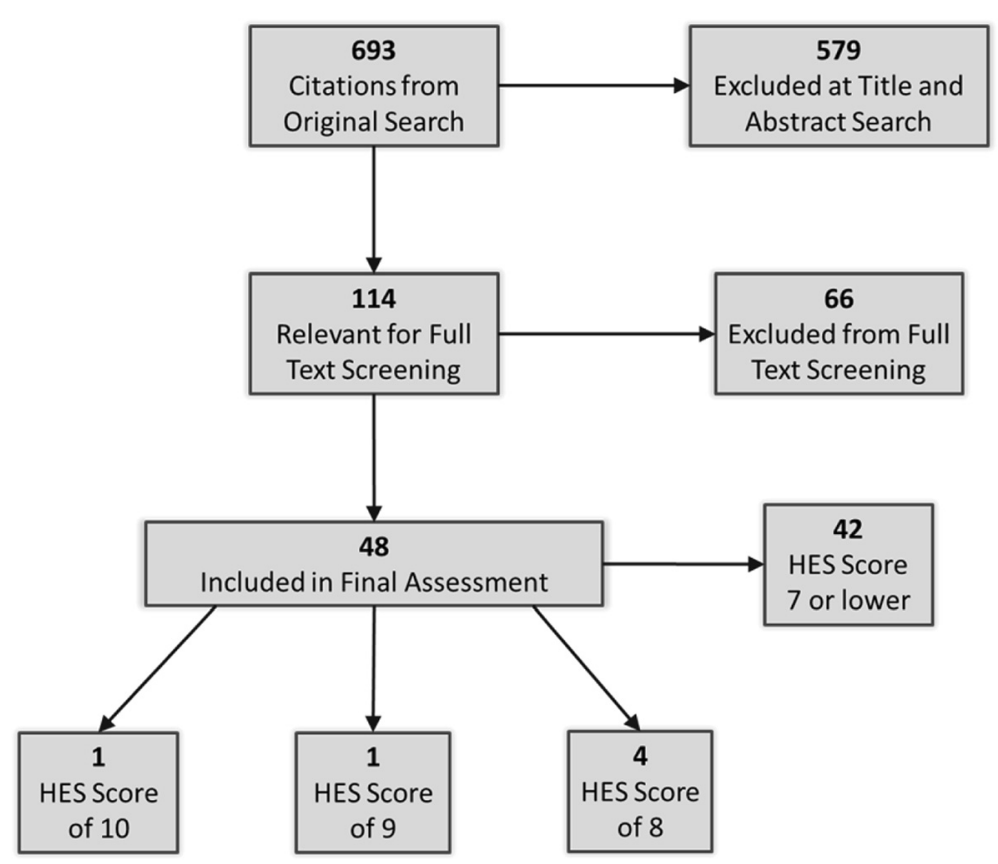

Fig. 1 Search flow diagram

The search strategy identified a total of 693 relevant documents. Upon further review, 114 documents were identified as including an introduction, discussion, or critique of a model or framework for some derivation of "knowledge to action". A table of all identified models or frameworks was then constructed. When the list was compiled, each was critiqued by CMD, using the description of the model or framework that was included in the identified document for six characteristics related to health equity. These criteria speak to factors associated with health equity challenges and are informed by the World Health Organization (WHO) Commission on the Social Determinants of Health [1], as well as previous work by the National Collaborating Centre for Determinants of Health [2], and key stakeholders (identified by name and organization in the acknowledgement section). The equity support characteristics included:

1) a specific focus, mention or consideration of equity, equality, justice, disadvantaged or vulnerable groups;

2) an inclusive conceptualization of knowledge (beyond scientific research) that ensures that different types of knowledge and/or ways of knowing might be considered in the evidence-base;

3) community members are represented and/or community participation is an explicit part of the model or framework;

4) interactions are supported across disciplines or sectors;
5) there is specific referral to the social, physical, political, and/or economic context of knowledge generation and use; and/or

6) there is an applied, proactive or problem-solving focus.

The models were assessed using a three-point scale $0=$ no obvious mention or inclusion in the description available, $1=$ some or partial mention or inclusion, and $2=$ this characteristic was clearly reflected. A total score was then calculated. This total score is referred to as the "health equity support" (HES) score. The results of this assessment can be found in Table 1.

\section{Findings}

\section{Overview}

In total, 48 unique models or frameworks for knowledge to action were found (Table 2). The majority of examples were from the last 15 years (as the inclusion criteria prioritized articles from 1997 to present), however, the Internet search, scan of reference lists and consultations with experts were not date limited, and as such, some models do fall outside this time period. An additional Excel file provides a list of these models with a brief description for each [see Additional file 1: Table S1].

Overall, there is a great variety among knowledge to action models or frameworks. These vary in the way they define and conceptualize knowledge (e.g. research evidence, innovations, ideas) and knowledge to action (e.g. translation, transfer, evidence-based practice, exchange, 
Table 2 Health equity analysis of knowledge to action models (rated on a scale where $0=$ none, $1=$ some/partial, and $2=$ clearly reflected)

\begin{tabular}{|c|c|c|c|c|c|c|c|}
\hline Model [Reference] & $\begin{array}{l}\text { Explicit focus on } \\
\text { equity or related } \\
\text { value }\end{array}$ & $\begin{array}{l}\text { Inclusive } \\
\text { conceptualization } \\
\text { of knowledge }\end{array}$ & $\begin{array}{l}\text { Stakeholder } \\
\text { engagement }\end{array}$ & $\begin{array}{l}\text { Explicit focus on } \\
\text { interactions across } \\
\text { jurisdictions or sectors }\end{array}$ & $\begin{array}{l}\text { Context } \\
\text { emphasized }\end{array}$ & $\begin{array}{l}\text { Applied, pro- } \\
\text { active, problem- } \\
\text { solving }\end{array}$ & $\begin{array}{l}\text { Total HES } \\
\text { Score }\end{array}$ \\
\hline Knowledge Brokering Frameworks [21] & 2 & 2 & 2 & 1 & 2 & 1 & 10 \\
\hline $\begin{array}{l}\text { A Model for Knowledge Translation and Exchange with Northern } \\
\text { Aboriginal Communities [25] }\end{array}$ & 2 & 2 & 2 & 0 & 2 & 1 & 9 \\
\hline A Framework for Research Transfer [22] & 0 & 1 & 2 & 1 & 2 & 2 & 8 \\
\hline Joint Venture Model of Knowledge Utilization [23] & 0 & 2 & 2 & 1 & 2 & 1 & 8 \\
\hline Translational Research Framework to Address Health Disparities [24] & 2 & 2 & 0 & 0 & 2 & 2 & 8 \\
\hline Ecohealth Model Applied to Translate Knowledge [26] & 2 & 1 & 1 & 2 & 2 & 0 & 8 \\
\hline Locally Based Research Transfer Model [35] & 0 & 0 & 2 & 1 & 2 & 2 & 7 \\
\hline User-Context Framework for Knowledge Translation [36] & 0 & 1 & 2 & 0 & 2 & 2 & 7 \\
\hline $\begin{array}{l}\text { Promoting Action on Research Implementation in Health Services } \\
\text { (PARIHS) Framework [37] }\end{array}$ & 0 & 2 & 1 & 0 & 2 & 2 & 7 \\
\hline Equity-Oriented Knowledge Translation Framework [38] & 2 & 1 & 0 & 0 & 2 & 2 & 7 \\
\hline The Knowledge Value Chain [39] & 0 & 2 & 1 & 1 & 1 & 2 & 7 \\
\hline Model for Large-Scale Knowledge Translation [40] & 1 & 1 & 0 & 2 & 2 & 1 & 7 \\
\hline Ottawa Model of Research Use [41] & 1 & 2 & 0 & 0 & 2 & 1 & 6 \\
\hline CHSRF Model of Knowledge Transfer and Exchange [42] & 0 & 0 & 2 & 0 & 2 & 2 & 6 \\
\hline Replicating Effective Programs Framework [43] & 0 & 1 & 2 & 0 & 1 & 2 & 6 \\
\hline The Sticky Knowledge Framework [44] & 0 & 1 & 1 & 0 & 2 & 2 & 6 \\
\hline $\begin{array}{l}\text { Tehran University of Medical Sciences (TUMS) Knowledge Translation } \\
\text { Model [45] }\end{array}$ & 0 & 1 & 1 & 0 & 2 & 2 & 6 \\
\hline $\begin{array}{l}\text { Collaborative Model for Knowledge Translation between Research } \\
\text { and Practice Settings [46] }\end{array}$ & 0 & 1 & 2 & 0 & 1 & 2 & 6 \\
\hline Knowledge Translation as part of the Research Cycle Model [19] & 1 & 0 & 2 & 0 & 2 & 1 & 6 \\
\hline $\begin{array}{l}\text { Conceptual Model for Considering the Determinants of Diffusion, } \\
\text { Dissemination, and Implementation [47] }\end{array}$ & 0 & 0 & 2 & 0 & 2 & 2 & 6 \\
\hline Model of Strategic Change [48] & 0 & 2 & 1 & 0 & 2 & 1 & 6 \\
\hline The Trinity Evidence-Based Practice Model [49] & 0 & 2 & 0 & 0 & 2 & 2 & 6 \\
\hline $\begin{array}{l}\text { Advancing Research and Clinical Practice through Close } \\
\text { Collaboration (ARCC) Model of Evidence-Based Practice in Nursing } \\
\text { and Healthcare [50] }\end{array}$ & 0 & 0 & 2 & 0 & 2 & 2 & 6 \\
\hline Knowledge to Action Process Model [9] & 0 & 2 & 0 & 0 & 2 & 2 & 6 \\
\hline Practical, Robust Implementation and Sustainability Model (PRISM) [20] & 0 & 1 & 1 & 0 & 2 & 2 & 6 \\
\hline Framework for Transferring Knowledge into Action [51] & 0 & 2 & 0 & 0 & 2 & 2 & 6 \\
\hline Four Levels of Knowledge Utilization [52] & 0 & 1 & 0 & 0 & 2 & 2 & 5 \\
\hline
\end{tabular}


Table 2 Health equity analysis of knowledge to action models (rated on a scale where $0=$ none, $1=$ some/partial, and $2=$ clearly reflected) (Continued)

\begin{tabular}{|c|c|c|c|c|c|c|c|}
\hline ACE Star Model of Knowledge Transformation [53] & 0 & 2 & 0 & 0 & 2 & 1 & 5 \\
\hline Pathman-PRECEDE Model for Knowledge Translation [54] & 0 & 1 & 1 & 0 & 1 & 2 & 5 \\
\hline Framework for Translating Evidence into Action [55] & 0 & 1 & 0 & 0 & 2 & 2 & 5 \\
\hline Diffusion of Innovations Model [56] & 0 & 1 & 1 & 0 & 1 & 1 & 4 \\
\hline Two-Communities or Two-Cultures Model [57] & 0 & 0 & 1 & 0 & 1 & 2 & 4 \\
\hline Framework for Changing Implementation Behaviour [58] & 0 & 0 & 0 & 1 & 2 & 1 & 4 \\
\hline Technology Transfer Model [59] & 1 & 1 & 0 & 0 & 1 & 1 & 4 \\
\hline Model of Research Utilization [60] & 0 & 0 & 1 & 0 & 2 & 1 & 4 \\
\hline Five-Point Knowledge Translation Framework [61] & 0 & 1 & 2 & 0 & 0 & 1 & 4 \\
\hline $\begin{array}{l}\text { Reach, Efficacy or Effectiveness, Adoption, Implementation, } \\
\text { Maintenance (RE-AlM) [62] }\end{array}$ & 0 & 1 & 1 & 0 & 1 & 1 & 4 \\
\hline Outcomes-Focused Knowledge Translation Intervention Framework [63] & 0 & 0 & 2 & 0 & 0 & 2 & 4 \\
\hline Stages of Research Utilization Model [64] & 0 & 0 & 1 & 0 & 1 & 2 & 4 \\
\hline $\begin{array}{l}\text { Interactive Systems Framework for Dissemination and } \\
\text { Implementation [65] }\end{array}$ & 0 & 2 & 2 & 0 & 1 & 1 & 4 \\
\hline lowa Model of Evidence-Based Practice [66] & 0 & 0 & 2 & 0 & 0 & 2 & 4 \\
\hline Six Knowledge Utilization Models [67] & 0 & 1 & 1 & 0 & 1 & 0 & 3 \\
\hline Measuring Knowledge Utilization Model [68] & 0 & 2 & 0 & 0 & 1 & 0 & 3 \\
\hline Research Utilization Model [69] & 0 & 0 & 0 & 0 & 1 & 2 & 3 \\
\hline Framework for Research Dissemination and Utilization [70] & 0 & 0 & 1 & 0 & 1 & 1 & 3 \\
\hline Translational Framework for Public Health Research [71] & 0 & 0 & 0 & 0 & 0 & 2 & 2 \\
\hline A Model for Evidence- Based Practice Implementation [72] & 0 & 0 & 0 & 0 & 2 & 0 & 2 \\
\hline Knowledge Translation within a Communication System Paradigm [73] & 0 & 0 & 0 & 0 & 0 & 1 & 1 \\
\hline
\end{tabular}

$0=$ no obvious mention or inclusion in the description available, $1=$ some or partial mention or inclusion, $2=$ this characteristic was clearly reflected 
implementation etc.). They also differ in their point of focus. Some conceptualize the use of knowledge for tactical or political purposes (models 22, 23 and 72 for example); others focus on the interactions, barriers and facilitators that are involved when knowledge is to be used to inform decisions (models 25, 42 and 59 for instance). Some are problem solving and applied in nature (such as models 40, 58 and 63), while others are more theoretical and philosophical in their approach (such as models 47 , 51, 56 and 57). It does appear that there has been some evolution in the field over the past 15 years. For example, our analysis identified at least four examples of models or frameworks that have emerged or have built upon others over time (e.g. Canadian Health Services Research Foundation (CHSRF) - now the Canadian Foundation for Healthcare Improvement - Model of Knowledge Transfer and Exchange [18]; Canadian Institutes for Health Research (CIHR) Knowledge Translation in the Research Cycle Model [19]; Equity-Oriented Framework [8]; and Practical, Robust Implementation and Sustainability Model (PRISM) [20]. There also appears to be more consistent focus on the context of knowledge to action as time has progressed.

\section{Relevance of models to health equity}

Table 1 lists the 48 models or frameworks that were identified and indicates their status with respect to six characteristics important in supporting health equity. Models could score a $0-2$ value for each of the six equity variables. A total score (a maximum of 12) was then calculated and this was termed the "health equity support" or HES score. The HES score is indicated for all models and the top six HES scored models are highlighted. This approach was not meant to be definitive and exclusionary, but instead is used as a systematic way to help identify models or frameworks, among a large number, that may have particular relevance for health equity while at the same time reporting some information for each model or framework found.

The models with the highest HES scores are the Knowledge Brokering Frameworks [21]; the Framework for Research Transfer [22]; the Joint Venture Model of Knowledge Utilization [23]; the Translational Research Framework to Address Health Disparities [24]; the Model of Knowledge Translation and Exchange with Northern Aboriginal Communities [25]; and the Ecohealth Model applied to knowledge translation [26]. These six models are discussed in detail below.

The Knowledge Brokering Frameworks outlined by Oldham and McLean [21] scored highest on the knowledge to action - health equity assessment. These are a series of three frameworks for knowledge brokering: a knowledge framework, a transactional framework, and a social change framework. The combination of these three frameworks had important implications for its high ranking in the health equity assessment. It explicitly supports an inclusive conceptualization of knowledge and although there is some emphasis on research evidence, it is not limiting. It prioritizes the engagement of a variety of stakeholders, and it has a strong emphasis on contextual factors. In addition, it discusses how the use of a social change framework in knowledge brokering could help address power differentials and encourage work that supports human rights.

The next highest scoring model in the health equity assessment was the model of Knowledge Translation and Exchange with Northern Aboriginal Communities [25]. This model focuses on knowledge translation specifically for northern Indigenous peoples. Using this model would include: establishing partnerships and trust with and among community members; undertaking capacity development activities; and engaging community field workers in all stages of research planning, data collection, analysis, interpretation, and dissemination. Researchers are called to have regular workshops for all members of the research team and make a commitment to return research results to the participants and communities first for verification and validation. There is also a commitment to make research and policy products relevant so that government decision makers might use them to inform policy and practice. The authors propose a true gold standard for integrated research and knowledge translation with vulnerable groups and include a specific sensitivity to the added ethical, cultural and spiritual dimensions of knowledge translation with Indigenous peoples. This model scores high on the health equity assessment because it has an explicit focus on equity and justice; it reflects an inclusive conceptualization of knowledge; it promotes meaningful and prolonged community engagement; and it is sensitive to contextual factors. The model scores lower on the problem-solving variable; although it is implicitly an applied approach, the authors do not explicitly describe whether research is chosen (or should be chosen) based on a specific issue or problem, nor do they describe how that priority setting might be approached. The model also does not emphasize work across jurisdictions or sectors, although it would be possible to see how this could be easily integrated.

There is a further group of four models that scored " 8 " in the health equity assessment. The Translational Research Framework to Address Health Disparities proposed by Fleming et al. [24] is a framework that is specifically focused on addressing health disparities by better aligning and translating research. This framework is made up of two interlinked conceptual models. The first model illustrates how to advance health disparities research through identifying disparities, examining their causes, developing and implementing interventions, and monitoring 
differential outcomes. The second model outlines knowledge to action and the different components of this in all realms of health research (e.g. the translation of knowledge from "bench" to "bedside" or from "bedside" to "community and public health practice"). The authors emphasize the need to connect biomedical to public health and clinical research, and to use research for real-world applications and community health intervention. The strengths of this model are that it focuses specifically on issues of health disparities, and there is a logical consideration of addressing problems associated with these disparities. There is also significant emphasis placed on contextual factors and the authors support an inclusive idea of knowledge.

Two other models: A Framework for Research Transfer [3] and The Joint Venture Model of Research Utilization [23] also scored "8" in the health equity review, and for similar reasons. These models touch on most aspects of the six features examined and had a strong emphasis on contextual features. Edgar and colleagues focus upon the interactions that happen in particular contexts, for example, individuals as they engage in organizations that in turn exist in social environments. Leadership, emotional intelligence and work, and socio-political environments are all featured components as well. In their framework, Nieva and colleagues identify that end users need a "change leader", and that intervention tools need to be adapted to local needs and to particular organizational contexts. Developments and adaptations of knowledge to action strategies for particular contexts of health equity could be supported by components of these models. In addition, both of these models have some reference to work across disciplines or sectors.

The final model to receive an " 8 " in the health equity assessment was the Ecohealth Model as applied to knowledge translation [26]; this is a combination of a health model and a knowledge to action model. The Ecohealth Model (described by Hancock [27] as well as others) links the fields of health and ecology and focuses on the health of humans, the health of other species, and the natural environment. Humans and human health are components of ecosystems. Arrendondo and Orozco [26] take this conceptualization and overlap it with a model of knowledge to action that includes the participation of researchers and other specialists in specific knowledge areas (and of different types of knowledge) with community members and other decision makers. The authors highlight that the pillars of transdisciplinarity, participation, and equity support an overlapped model of Ecohealth and knowledge to action.

\section{Discussion}

\section{Review of findings}

The purpose of this project was to identify existing knowledge to action models or frameworks and critically examine their utility for promoting or supporting health equity. Forty-eight knowledge to action models or frameworks were identified. All of the models were then assessed across six characteristics relevant for supporting health equity. While no models scored full marks, the highest scoring models were found to have features relevant to advancing health equity.

In the assessment, we propose six characteristics that could be important markers: 1) an explicit mention of equity, justice or similar concept; 2) the involvement of various stakeholders; 3 ) an explicit focus on engagement across multiple sectors or disciplines; 4 ) the use of an inclusive conceptualization of knowledge; 5) the recognition of the importance of contextual factors; and, 6) a proactive or problem-solving focus. Specific populations, topics and solutions are marginalized, ignored, or not acted upon when, for example, only certain knowledge is considered valuable, when we don't have a specific focus on equity or justice, and when we don't work across sectors or consider contextual determinants of health $[1,2]$.

\section{Assessment of what might be missing in the models or frameworks}

Health inequities are often enduring and profound. Commonly, factors that lead to inequity are deeply embedded in systems, processes, and norms of societies and cultures [5]. In addressing the "causes of the causes" [28] of health inequities, multisectoral approaches, focused on recognizing and addressing inequities, have been heralded $[1,2]$. Of the six health equity supportive characteristics looked for in the knowledge to action models an explicit mention of multisectoral approaches or actions in knowledge translation was largely absent with only one model within the top six, the Ecohealth Model Applied to Translate Knowledge [26], strongly demonstrating integration of this component.

In order to inform decisions and change situations of inequity, adopting, collecting, synthesizing or valuing various new pieces of knowledge is often required. This can require difficult shifts from norms of practice, current and ingrained behavior, or systems of engagement, especially if considering work that might span disciplines or sectors. The creation of supportive structures in this process is ideal [3]. Knowledge brokering involves guided actions that can link producers of knowledge, including knowledge about inequities, with possible knowledge users [29]. This is sometimes conceptualized by focusing on guided interactions between researchers and decision makers [18] where these two groups are largely situated in different realms or communities. Knowledge brokers, whether whole organizations or specific individuals or groups, help to facilitate interactions; their goal is to support understanding and relationship building among diverse stakeholders. When a more 
full understanding of the various goals and professional cultures is established, new partnerships can be forged. This provides an opportunity for decisions to be informed by research knowledge $[18,30]$. The Knowledge Brokering Frameworks outlined by Oldham and McLean [21] scored highest for supporting health equity among the 48 models identified. Included in this model are a knowledge framework, a transactional framework, and a social change framework. These frameworks explicitly support an inclusive conceptualization of knowledge; recognize the importance of contextual determinants of knowledge to action as well as the engagement of a variety of stakeholders. They have been designed to consider the social contexts and disrupt the power differentials that are at the heart of health inequities. Knowledge brokering has been an approach supported by Canadian organizations previously, including the Canadian Health Services and Research Foundation (currently the Canadian Foundation for Healthcare Improvement) and the Canadian Coalition for Global Health Research. It may be time to revisit this concept and these approaches when considering further actions for knowledge translation, health equity and the social determinants on health. It is not clear exactly how knowledge brokering could best be approached to ensure more effective action to address health inequity, however, this area represents an avenue for further discussion and scholarship as well.

\section{Recognized strengths in current models or frameworks}

Links between vulnerability of specific populations and factors of social and physical environments are clear [31, 32]. There are many examples of models or frameworks where knowledge to action is conceptualized as holistic and interconnected and where features of context and environment are highlighted as important health and health equity determinants. Environmental features differentially impact sub-populations, and thus privilege some concerns or issues over others [33]. For this reason, models such as the Ecohealth Model [26] or the model of Knowledge Translation and Exchange with Northern Aboriginal Communities [25] have appeal. They have utility when considering the dynamic social, cultural, and historic features [33] surrounding knowledge to action work. The Jardine and Furgal [25] model, emanating from a community-based partnership for indigenous health research, has a strong emphasis on and recognition of the cultural, social, spiritual and geographic contexts; various types of knowledge and ways of knowing; and the essential nature of stakeholder engagement and leadership. Similarly, it is helpful to look towards research ethics models that have been developed for work with indigenous people [34] to further consider how participatory, culturally sensitive, integrative, or community-based approaches may be useful to inform knowledge to action and health equity pursuits. These models have not yet been used widely outside indigenous communities, and there remains distinct potential for their uptake in different arenas of action to advance health equity.

\section{Limitations}

Our intention was to identify a group of models, especially those referred to over the past 15 years, in order to determine which ones may have utility in supporting health equity efforts. We understand that every existing model was not identified and that our assessment process was not formally validated. We searched only four prominent databases and we did not contact study authors for additional unpublished information about the different models or frameworks. We did not search "evidence-based" as a unique keyword (as in evidencebased medicine; evidence-based practice), however, we did include these types of models in our list if they were found in the documents amassed in the search strategy outlined in Fig. 1.

The characteristics making up the "heath equity assessment" score used to assess the models were generated from the literature and from discussions with key stakeholders (listed in the acknowledgements for this paper). Each of the characteristics were given the same weight. The assessment relied on the model descriptions which were often only briefly included in the literature. This may not accurately capture all aspects and nuance of health equity support, and does not always take into account how effectively a model can be applied in practice. The assessment was completed by just one person (primary author). We recognize that there may have been some variation in assessments if done by multiple independent reviewers, especially in interpretations of "partial" and "clearly" reflected.

\section{Conclusion}

Forty-eight models of knowledge to action were identified and assessed based on six characteristics of health equity; the highest score being a possible 12. There was no single "perfect" model. Six models, all scoring between 8 and 10 of a maximum 12 points, exist as promising examples of knowledge to action models that may have utility for supporting health equity. Each could be strengthened in some way to make them more useful in supporting health equity by considering the six characteristics used in this review. Of particular interest is knowledge brokering as well as the use of holistic and cross-sector models of knowledge to action that consider environmental and contextual determinants. These are specific future avenues identified in this project. As there was no single ideal model found, discussion could also centre on what an ideal health equity, knowledge to action model might look like and if thought beneficial, how this could be developed, tested and used 
effectively. This conversation has been recently taken up by others [35] and this discussion could be further informed by those with knowledge and experience in knowledge brokering, as well as with Ecohealth approaches, and participatory and integrative research, and knowledge translation with Indigenous people.

\section{Implications for public health}

- Existing knowledge translation models can help guide the application of knowledge to inform public health action to improve health equity. The six models analysed in detail exist as promising examples of knowledge to action models that have utility for supporting action on the social determinants of health and improving health equity.

- The most relevant models are those which embody principles and values reflective of equity and social justice.

- These models explicitly identify equity as a goal; value the involvement of various stakeholders; prioritize multisectoral engagement; use an inclusive conceptualization of knowledge; recognize the importance of contextual factors; and have a proactive or problem-solving approach.

- There is room to develop and test more robust equity supporting models. This conversation will require attention to the criteria proposed in this paper.

\section{Additional file}

Additional file 1: Table S1. Description of Each Identified Knowledge to Action Models. Description of data: A tabulated summary of the 48 KTA models identified and evaluated including a brief description of each model.

\section{Authors' information}

CMD: PhD, Assistant Professor and Research Scientist, Department Public Health Sciences, Queen's University, 63 Fifth Field Company Lane, Kingston, ON, K7L 3N6 CANADA T: +1 613 533-6000 x 79518 F: +1 613 548-1381. SNE: MHSc, Knowledge Translation Specialist, National Collaborating Centre for Determinants of Health, St Francis Xavier University, P.O. Box 5000 Antigonish, NS, B2G 2WG.

CC: BSc, Scientific Director, National Collaborating Centre for Determinants of Health, St Francis Xavier University, P.O. Box 5000 Antigonish, NS, B2G 2WG.

\section{Acknowledgements}

We gratefully acknowledge Dr. Louise Potvin, Faculty of Medicine, University of Montreal; Dr. Maureen Dobbins, National Collaborating Centre for Methods and Tool; Erica Di Ruggiero, Emma Cohen, and Rachel McClean, Institute of Population and Public Health, Canadian Institutes of Health Research; Dr. Allan Ronald, National Collaborating Centre for Infectious Diseases (former); and Dr. Joel Kettner, National Collaborating Centre for Infectious Diseases who reviewed earlier versions of this paper. We would also like to acknowledge reviews by members of the Knowledge Dissemination Committee of the Canadian Council on the Social Determinants of Health as well as analysts in the Health Determinants and Global Initiatives, Strategic Initiatives and Innovations Directorate, Public Health Agency of Canada. We are also grateful to research associates Ariel Pulver and Bryn Pinkerton who assisted with components of the search and compilation of Table 2.

\section{Sources of support}

Salary support for the first author and research assistants was provided through an Emerging Researcher Award from the Population Health Intervention Research Network. Additional funding was provided by the National Collaborating Centre for Determinants of Health, National Collaborating Centre for Methods and Tools and the National Collaborating Centre for Infectious Diseases.

\section{Disclaimers}

The views expressed in the submitted article are the authors own and not an official position of the institution or funder.

\section{Author details}

${ }^{1}$ Department Public Health Sciences, Queen's University, 63 Fifth Field Company Lane, Kingston, ON K7L 3N6, Canada. ${ }^{2}$ National Collaborating Centre for Determinants of Health, St Francis Xavier University, P.O. Box 5000, Antigonish, NS B2G 2WG, Canada.

Received: 26 September 2014 Accepted: 22 May 2015 Published online: 29 May 2015

\section{References}

1. Commission on Social Determinants of Health. Final Report: Closing the gap in a generation: health equity through action on the social determinants of health. Geneva: World Health Organization; 2008.

2. National Collaborating Centre for Determinants of Health. Integrating social determinants of health and health equity into Canadian public health practice: environmental scan 2010. Antigonish,NS: NCCDH; 2011.

3. World Health Organization. Bridging the "know-do" gap: Meeting on Knowledge Translation in Global Health: 10-12 October. Geneva: World Health Organization; 2005.

4. Bowen S, Botting I, Roy J. Promoting action on equity issues: a knowledgeto-action handbook. Edmonton, AB: School of Public Health, University of Alberta; 2011

5. Whitehead M. The concepts and principles of equity and health. Int J Health Services. 1992;22(3):429-45.

6. Rycroft-Malone J. Theory and knowledge translation: setting some coordinates. Nurs Res. 2007:56(4 Suppl):S78-85.

7. World Health Organization. Policies and strategies to promote equity in health. Copenhagen: World Health Organization; 1992.

8. Tugwell PS, Santesso NA, O'Connor AM, Wilson AJ. Knowledge translation for effective consumers. Phys Ther. 2007:87(12):1728-38.

9. Graham ID, Logan J, Harrison MB, Straus SE, Tetroe J, Caswell W, et al. Lost in knowledge translation: time for a map? J Continuing Ed Health Prof 2006:26(1):13-24 
10. McKibbon KA, Lokker C, Wilczynski NL, Ciliska D, Dobbins M, Davis DA, et al. A cross-sectional study of the number and frequency of terms used to refer to knowledge translation in a body of health literature in 2006: a Tower of Babel. Implement Sci. 2010;5(1):16.

11. Davison CM. Knowledge translation: Implications for evaluation. N Dir Eval. 2009;2009(124):75-87.

12. Pablos-Mendez A, Chunhuras S, Lansang MA, Shademani R, Tugwell P. Knowledge translation in global health. Bull World Health Organ. 2005;83(10):723.

13. Straus SE, Tetroe J, Graham I. Defining knowledge translation. Can Med Assoc J. 2009;181(3-4):165-8.

14. Straus SE, Graham ID, Mazmanian PE. Knowledge translation: resolving the confusion. J Con Ed Health Prof. 2006;26(1):3-4.

15. Reimer-Kirkham S, Varcoe C, Browne AJ, Lynam MJ, Khan KB, McDonald H. Critical inquiry and knowledge translation: exploring compatibilities and tensions. Nurs Phil. 2009;10(3):152-66.

16. Santesso N, Tugwell P. Knowledge translation in developing countries. J Con Ed Health Prof. 2006;26(1):87-96.

17. Welch V, Ueffing E, Tugwell P. Knowledge translation: An opportunity to reduce global health inequalities. J Int Devel. 2009;21(8):1066-82.

18. Canadian Health Services Research Foundation. The theory and practice of knowledge brokering in Canada's health system: a report based on a CHSRF national consultation and a literature review. Ottawa: CHSRF; 2003.

19. Canadian Institutes for Health Research. Knowledge Translation Strategy 2004-2009. In: Innovation in Action. Ottawa: CIHR; 2004.

20. Feldstein AC, Glasgow RE. A practical, robust implementation and sustainability model (PRISM). Joint Comm J Qual and Patient Safety. 2008;34(4):228-43.

21. Oldham G, McLean R. Approaches to knowledge-brokering. Int Institute for Sustainable Devel. 1997;23(10):6.

22. Nieva VF, Murphy R, Ridley N, Donaldson N, Combes J, Mitchell P, et al. From science to service: a framework for the transfer of patient safety research into practice. In: Henriksen K, Battles JB, Marks ES, editors. Advances in patient safety: from research to implementation, Concepts and Methodology, vol. 2. Rockville MD: Agency for Healthcare Research and Quality, US; 2005. p. 441-53.

23. Edgar L, Herbert R, Lambert S, MacDonald JA, Dubois S, Latimer M. The joint venture model of knowledge utilization: A guide for change in nursing. Nursing Leadership: Acad of Can Exec Nurses. 2006;19(2):41-55.

24. Fleming ES, Perkins J, Easa D, Baker RS, Southerland WM, Dottin R, et al. The role of translational research in addressing health disparities: a conceptual framework. Ethn Dis. 2008;18(2 Suppl 2):S2.

25. Jardine C, Furgal C. Knowledge translation with northern Aboriginal communities: a case study. Can J Nurs Res. 2010;42(1):119-27.

26. Arredondo A, Orozco E. Application of the ecohealth model to translate knowledge into action in the health sciences. Environ Health Perspect. 2012;120(3):104-5.

27. Hancock T. Towards healthy and sustainable communities: Health, environment and economy at the local level. Presentation at the 3rd Symposium on Environmental Health: November 22. Toronto, ON: Faculty of Environmental Studies, York University; 1990.

28. Marmot M. Social determinants of health inequalities. Lancet. 2005;365(9464):1099-104.

29. Meyer M. The rise of the knowledge broker. Sci Comm. 2010;32(1):118-27.

30. Lomas J. The in-between world of knowledge brokering. BMJ. 2007;334(7585):129.

31. Macintyre S, Ellaway S, Cummins S. Place effects on health: how can we conceptualize, operationalize and measure them? Soc Sci Med. 2002;55:125-39.

32. Schulz AJ, Kannan S, Dvonch JT, Israel BA, Allen A, James SA, et al. Social and physical environments and disparities in risk for cardiovascular disease: the healthy environments partnership conceptual model. Environ Health Perspect. 2005;113(12):1817.

33. Smylie J, Martin CM, Kaplan-Myrth N, Steele L, Tait C, Hogg W. Knowledge translation and indigenous knowledge. Int J of Circumpolar Health. 2004;63 Suppl 2:139-43.

34. Canadian Institutes of Health Research, National Sciences and Engineering Research Council of Canada, Social Science and Humanities Research Council. Chapter 9: Research involving the First Nations, Inuit and Metis people of Canada. In: Tri-council policy statement 2 (TCPS 2) - 2nd edition of tri-council policy statement: ethical conduct for research involving humans. Ottawa: Government of Canada; 2010.
35. Anderson M, Cosby J, Swan B, Moore H, Broekhoven M. The use of research in local health service agencies. Soc Sci Med. 1999;49(8):1007-19.

36. Jacobson N, Butterill D, Goering P. Development of a framework for knowledge translation: understanding user context. J Health Services \& Research Policy. 2003;8(2):94-9.

37. Rycroft-Malone J. The PARIHS framework-A framework for guiding the implementation of evidence-based practice. J Nurs Care Qual. 2004;19(4):297-304.

38. Tugwell P, Robinson V, Grimshaw J, Santesso N. Systematic reviews and knowledge translation. Bull World Health Organ. 2006;84(8):643-51.

39. Landry R, Amara N, Pablos-Mendes A, Shademani R, Gold I. The knowledgevalue chain: A conceptual framework for knowledge translation in health. Bull World Health Organ. 2006;84(8):597-602.

40. Pronovost PJ, Berenholtz SM, Needham DM. Translating evidence into practice: a model for large scale knowledge translation. BMJ. 2008;337(Journal Article):a1714.

41. Logan J, Graham ID. Toward a comprehensive interdisciplinary model of health care research use. Sci Comm. 1998;20(2):227-46.

42. Canadian Health Services Research Foundation. Is Research Working for You? A Self-Assessment Tool and Discussion Guide for Health Services Management and Policy Organizations. Ottawa: CHSRF; 2000.

43. Kilbourne AM, Neumann MS, Pincus HA, Bauer MS, Stall R. Implementing evidence-based interventions in health care: application of the replicating effective programs framework. Implementation Sci. 2007;2(1):42.

44. Elwyn G, Taubert M, Kowalczuk J. Sticky knowledge: A possible model for investigating implementation in healthcare contexts. Implementation Sci. 2007;2(1):44.

45. Majdzadeh R, Sadighi J, Nejat S, Mahani AS, Gholami J. Knowledge translation for research utilization: design of a knowledge translation model at Tehran University of Medical Sciences. J of Cont Ed in the Health Prof. 2008;28(4):270-7.

46. Baumbusch JL, Kirkham SR, Khan KB, McDonald H, Semeniuk P, Tan E, et al. Pursuing common agendas: a collaborative model for knowledge translation between research and practice in clinical settings. Res Nurs Health. 2008;31(2):130-40.

47. Greenhalgh T, Robert G, Macfarlane F, Bate P, Kyriakidou O. Diffusion of innovations in service organizations: systematic review and recommendations. Milbank Q. 2004;82(4):581-629.

48. Pettigrew A, Whipp R. Managing Change for Competitive Success. Oxford, UK: Blackwell Publishing; 2003. p. 26.

49. Vratny A, Shriver D. A conceptual model for growing evidence-based practice. Nurs Adm Q. 2007;31(2):162-70.

50. Melnyk B, Fineout-Overholt E. Evidence-based practice. In: Nursing and healthcare: A guide to best practice. Philadelphia: Lippincott Williams \& Wilkins; 2005.

51. Ward V, House A, Hamer S. Developing a framework for transferring knowledge into action: a thematic analysis of the literature. J Health Serv Res Pol. 2009;14(3):156-64.

52. Backer TE. Knowledge utilization: The third wave. Sci Comm. 1991;12(3):225-40.

53. Stevens KR. ACE Star Model of EBP: knowledge transformation. In: Academic Center for Evidence-based Practice. San Antonio: The University of Texas Health Science Center; 2004.

54. Davis D, Evans M, Jadad A, Perrier L, Rath D, Ryan D, et al. The case for knowledge translation: shortening the journey from evidence to effect. BMJ. 2003;327(7405):33-5.

55. Swinburn B, Gill T, Kumanyika S. Obesity prevention: a proposed framework for translating evidence into action. Obes Rev. 2005;6(1):23-33.

56. Rogers EM. Diffusion of innovations. 3rd ed. New York: The Free Press; 2003.

57. Caplan N. The Two-Communities Theory and Knowledge Utilization. Am Behavioral Scientist. 1979;22(3):459-70

58. Grol R, Grimshaw J. Evidence-based implementation of evidence-based medicine. Joint Comm J Qual Improv. 1999;25(10):503-13.

59. Kraft JM, Mezoff JS, Sogolow ED, Neumann MS, Thomas PA. A technology transfer model for effective HIV/AIDS interventions: Science and practice. AIDS Ed Prev. 2000;12(5 Suppl):7-20.

60. Stetler CB. Updating the Stetler Model of research utilization to facilitate evidence-based practice. Nurs Outlook. 2001;49(6):272-9.

61. Lavis JN, Robertson D, Woodside JM, McLeod CB, Abelson J. How can research organizations more effectively transfer research knowledge to decision makers? Milbank Q. 2003;81(2):221-48.

62. Dzewaltowski DA, Glasgow RE, Klesges LM, Estabrooks PA, Brock E. RE-AIM: evidence-based standards and a Web resource to improve translation of research into practice. Annals of Behavioral Med. 2004;28(2):75-80. 
63. Doran DM, Sidani S. Outcomes-focused knowledge translation: a framework for knowledge translation and patient outcomes improvement. Worldviews Evid Based Nurs. 2007:4(1):3-13.

64. Davis SM, Peterson JC, Helfrich CD, Cunningham-Sabo L. Introduction and conceptual model for utilization of prevention research. Am J Preventive Med. 2007:33(1):S1-5.

65. Wandersman A, Duffy J, Flaspohler P, Noonan R, Lubell K, Stillman L, et al. Bridging the gap between prevention research and practice: The interactive systems framework for dissemination and implementation. Am J of Community Psychol. 2008;41(3-4):171-81.

66. Titler MG, Kleiber C, Steelman VJ, Rakel BA, Budreau G, Everett LQ, et al. The lowa model of evidence-based practice to promote quality care. Critical Care Nurs Clinics of North Am. 2001:13(4):497-509.

67. Weiss CH. The Many Meanings of Research Utilization. Public Adm Rev. 1979;39(5):426-31.

68. Rich RF. Measuring knowledge utilization: processes and outcomes. Knowl Pol. 1997:10(3):11-24

69. Rosswurm MA, Larrabee JH. A Model for Change to Evidence-Based Practice. J of Nurs Scholarship. 1999;31(4):317-22

70. Dobbins M, Ciliska D, Cockerill R, Barnsley J, DiCenso A. A Framework for the Dissemination and Utilization of Research for Health-Care Policy and Practice. Online J of Knowl Syn for Nurs. 2002;9(1):149-60.

71. Ogilvie D, Craig P, Griffin S, Macintyre S, Wareham NJ. A translational framework for public health research. BMC Public Health. 2009;9(1):116.

72. Aarons GA, Hurlburt M, Horwitz SM. Advancing a conceptual model of evidence-based practice implementation in public service sectors. Adm Policy Ment Health. 2011;38(1):4-23.

73. Beal GM, Meehan P. Knowledge Production and Utilization. In: Annual Meeting of the Rural Sociological Society. September 1978. San Francisco: Rural Sociological Society; 1978.

\section{Submit your next manuscript to BioMed Central and take full advantage of:}

- Convenient online submission

- Thorough peer review

- No space constraints or color figure charges

- Immediate publication on acceptance

- Inclusion in PubMed, CAS, Scopus and Google Scholar

- Research which is freely available for redistribution 